\title{
Trends of delayed first antenatal care visit among pregnant women in Ethiopia based on the EDHS 2000- 2016 data: Multivariate decomposition analysis
}

Asaye Gebeyehu ( $\nabla$ asaye2127stat@gmail.com )

Debre Tabor University

Achenef Muche

University Of Gondar

Mehari Merid

University Of Gondar

\section{Research Article}

Keywords: Delay, Trends, Antenatal care, Decomposition analysis, Ethiopia

Posted Date: December 2nd, 2020

DOI: https://doi.org/10.21203/rs.3.rs-109954/v1

License: (a) (i) This work is licensed under a Creative Commons Attribution 4.0 International License. Read Full License 


\section{Abstract}

Background: Timing of first antenatal care visiting is crucial for women and fetus health. However, most of the women had delayed antenatal care visits and lacked early detection of existing complications. Hence, this study aimed to assess the trends and magnitude of delayed first antenatal care visits among pregnant women in Ethiopia.

Method: This study used cross-sectional data analysis on Ethiopian Demographic and Health Surveys. A total weighted sample of 2146 in 2000, 2051 in 2005, 3368 in 2011, and 4740 in 2016 women who received at least one antenatal care visit in the past five years before each survey were included. Stata 14.1 software was used for data management and further analysis. Trends and multivariate logistic decomposition analyses were employed to examine the change in delayed first antenatal care visits with sampling weighting for the survey data. The $95 \%$ confidence interval was used for considering statistical significance.

Results: The proportion of delayed first antenatal care visit was declined from 76.8 (95\% Cl: $75.1-78.6)$ in 2000 to 67.3 (95\% Cl: $65.9-68.6)$ in 2016. The decomposition analysis showed that $39 \%$ of the overall change in delayed first antenatal care visit over time was due to differences in characteristics whereas about $61 \%$ was due to the effect of characteristics. The significant contributing factors for the decline of delayed first antenatal care visit were the place of residence, husband's education, women occupation, told about pregnancy complications, caesarean delivery, and family size.

Conclusion: The proportion of delayed first antenatal care visits has been declined over time in Ethiopia, but still it remains high. More of the overall change in delayed first antenatal care visit was attributed to a change in health behavior among pregnant women. Public health interventions or programs such as health education and behavioral change communication targeting the rural residents, lower economic status, and family size would be suggested to decline delayed first antenatal care visit.

\section{Background}

Antenatal care (ANC) is essential care that is given by professional health workers during pregnancy and childbearing to minimize and treat or manage existing and a leading cause of maternal and newborns mortality [1]. The World health organization recommended that every pregnant woman who is either with or without complication should have a minimum of four and above ANC visits, of which first ANC visits take place in the first trimesters to reduce any pregnancy and childbearing complications [1, 2]. The recommended first ANC visit has undertaken within 16 weeks or four months but not later in the federal ministry of health, Ethiopia [3]. Globally, about $86 \%$ of pregnant women have received at least once antenatal care visits of which $65 \%$ of women received at least four and above antenatal care visits while in Sub-Saharan Africa, 55\% of pregnant women had received at least four and above antenatal care visits [4]. In Ethiopia, only $32 \%$ of the women received four and above antenatal care visits [5]. Timing of first antenatal care visits can affect the quality of antenatal care and under-utilize of the recommended ANC visits that leading to adverse pregnancy outcomes, which are reduced through proper medication and treatments at risk of pregnancy [6]. Ethiopia is one of the countries that faced the highest maternal and infant mortality and morbidity. As the Ethiopian Demographic and Health Survey (EDHS) report stated that the pregnancy-related mortality ratio was 871 per 
100,000 in the years 2000, it was 673 in 2005 per 100,000 live births, 676 in 2011, and 412 in 2016 per 100,000 live births [5]. Pregnancy complications are leading to a higher maternal and child disability as well as death in developing countries [7]. Globally, for every day, about 810 women die due to pregnancy complications or births [8]. Nearly one-third of million maternal death has occurred a year and about $94 \%$ of the death occurred in developing countries [9]. More than halves of these deaths of women have occurred in sub-Saharan countries [2] which included Ethiopia had a higher maternal mortality ratio due to lower utilization of ANC care services and they are postponed first ANC visit in the second and third trimester $[5,10]$.

In Ethiopia, the latest EDHS 2016 indicated that 37\% of women had no ANC visits in the last five years before the survey, and $20 \%$ of pregnant women made their first ANC visit before the four months whereas urban women have made their ANC visits earlier than rural resident women [5]. When women delaying for their first ANC visits, they have a higher risk of poor pregnancy outcomes, maternal and child mortality [11]. Consequently, pregnant women would have been missed the intended benefits of ANC could include early detection and management of existing health conditions and complications of pregnancy to prevent the lifethreatening maternal and newborns condition. Thus, delaying for antenatal care makes it difficult to accomplish effectively the regular first ANC visits that increase the well-being of maternal and pregnancy outcomes $[2,12]$. The low ANC coverage, failing to attend, and delayed first antenatal care visits among pregnant women are a significant problem in Ethiopia [13]. Despite achieving improvement results in health indicators including the accessibility of maternal health care services and reduction of child mortality over time [10], Ethiopia is one of the countries with the highest rate of delayed first antenatal care visiting in subSaharan Africa. Different studies have been identified determinants of maternal health care services utilization were included under predisposing, enabling, and needing factors [14, 15]. The previous studies on the influences of delayed initiation of ANC in local areas. But no study focuses on the trends and identify the contributing factors for the change in delayed first antenatal care visit in Ethiopia over the studying period. Studying the change in delayed first ANC visit by using multivariate decomposition analysis to identify the significant factors contributing for the change in delayed first ANC visit over time that have become important to targeting interventions on factors that decreasing delayed first ANC visit and to forward policies and programs that focusing on reducing of delayed first antenatal care visit in Ethiopia. Therefore, this study is aimed to address the magnitude and trends as well as contributing factors for change in delayed first ANC visit over time by using multivariate decomposition analysis based on the 2000-2016 Ethiopian Demographic and Health Survey (EDHS).

\section{Method And Materials}

\section{Data}

This is a cross-sectional data analysis based on the 2000, 2005, 2011, and 2016 Ethiopian Demographic and Health Survey (EDHS). The EDHS utilized stratified two-stage cluster sampling. Under stratification, each region was separated into rural and urban areas. In the first stage, 539 clusters (enumeration areas), of which 138 in urban areas and 401 in rural areas and have selected 27 households by using systematic sampling with proportional probabilities for 2000 EDHS, 540 clusters (enumeration areas), of which 145 in urban areas and 395 in rural areas and have selected participants between 24 to 32 households from each cluster in 2005 
EDHS, 624 clusters (enumeration areas), of which 187 in urban areas and 437 in rural areas and selected participants from households per cluster for 2011 EDHS and finally 645 clusters (enumeration areas), of which 202 in urban areas and 443 in rural areas and select fixed 28 households with equal probability from list of households per cluster in 2016 EDHS. At the second stage, the list of households carried out in each cluster and have selected households systematically with proportional or equal probabilities. The detailed information about sampling procedures was presented in the EDHS report [5, 16-18].

\section{Source and study populations}

The source population was all women who had received antenatal care visits in the past five years for each survey in Ethiopia whereas the study population was all women who had received first antenatal care visits in the past fifteen years for each survey in the selected clusters of Ethiopia.

\section{Study variables}

\section{Outcome variable}

The women were asked to report the timing of the first antenatal care visits in each consecutive survey. The outcome variable was delayed first antenatal care visits among women who received at least one ANC visit. The response variable was a random variable and had two possible values. So, the response variable $Y_{i}$ for $i^{\text {th }}$ women was measured as a binary outcome variable and two possible values $Y \mathrm{i}=1$, if women had received delayed $A N C$ visit and $Y_{i}=0$ if women had received early $A N C$ visit.

\section{Independent variables}

The independent variables in this study were divided into predisposing, enabling, and need factors. The predisposing variables were the demographic and socio-cultural characteristics of the women that pre-exist to their health condition including maternal age, marital status, religion, women occupation, husband occupation, women education, husband education, parity, family size, and the number of living children. The enabling (economic) factors revealed that the means or facilitators needed to access maternal health care services that containing wealth index, head of household, distance to the health facility, source of information such as radio, television, and newspaper as well as the services. The third category of independent variables was need factors that reflect the perceived health status of the individual and were also the most potential causes leading to the health conditions. This includes contraceptive use, caesarean delivery, wantedness of pregnancy, told about pregnancy complication, and termination of pregnancy [19].

\section{Data collection procedures}

This study was done based on the Ethiopian demographic and health survey (EDHS) data by accessed from DHS program database website www.measuredhs.com after permission was granted through an online request by describing the objective of the study. The raw data were obtained from women who had received antenatal care visits in the selected clusters of a country through a structured and pre-tested questionnaire.

\section{Data management and analysis}


After clearing and editing, the raw data were weighted by using sampling weight, primary sampling unit, and strata to obtain the nationally representative sample of the surveys and the analysis was done using STATA 14.1 software. In this study, data analysis consists of three important parts. First, the descriptive and summary statistics of the study population. Second, appending the data from 2000, 2005, 2011, and 2016 EDHS together after extracting relevant variables for trends and multivariate decomposition analysis in the third section. This decomposition analysis was to identify factors that contribute to the proportional change in delayed first antenatal care visit in Ethiopia. The result obtained from decomposition analysis could reflect two effects, which are decomposition change and change in the effect of characteristics for selected important independent variables.

\section{Trends and decomposition analysis}

The descriptive analysis was used to describe the trends for each important stratified selected characteristics of respondents and assessed separately for each pair of 2000-2005, 2005-2011, 2011-2016, and 2000-2016 surveys. Multivariate decomposition analysis was conducted to answer the main factors contributing to the difference in the proportion of delayed first antenatal care visits over the study period of EDHS 2000 and 2016. This analysis targeted how the proportion of delayed first antenatal care visit responds to differences in women's characteristics and how these factors change across the surveys conducted at different times. The changes in delayed first antenatal care visits over time can be attributed to the compositional difference between surveys and differences in the effects of the selected independent variables. Therefore, the observed change in delayed first antenatal care visit between surveys is additively divided into explained characteristics (endowments) component and unexplained characteristics (coefficient) component.

In the nonlinear model, the response variable is a function of a linear combination of predictors and regression coefficients.

$$
\mathrm{Y}=\mathrm{F}(\mathrm{X} \beta)=\operatorname{logit}(\mathrm{Y})=\mathrm{X} \beta
$$

where $Y$ represent the dependent variable

\section{$X$ deals with a set of independent variables}

$\beta$ denote set of regression coefficients

The proportion of delayed first antenatal care visit difference between any two surveys of A and B of all four consecutive EDHS surveys of the delayed first ANC visits can be decomposed as

$$
\mathrm{Y}_{\mathrm{A}}-\mathrm{Y}_{\mathrm{B}}=\mathrm{F}\left(\mathrm{X}_{\mathrm{A}} \beta_{\mathrm{A}}\right)-\left(\mathrm{X}_{\mathrm{B}} \beta_{\mathrm{B}}\right)
$$

The recent 2016 EDHS and reference 2000 EDHS datasets can be denoted by A and B respectively. For logistic regression, the log-odds or logit of delayed first ANC visits. 


$$
\operatorname{logit}(A)-\operatorname{logit}(B)=\left[\beta_{0 A}-\beta_{0 B}\right]+\sum X_{i j B} *\left[\beta_{i j A}-\beta_{i j B}\right]+\sum \beta_{i j B} *\left[X_{i j A}-X_{i j B}\right]
$$

where; $\beta_{O B}$ is the intercept in the regression equation for EDHS 2000

$\beta_{0 A}$ is the intercept in the regression equation for EDHS 2016

$\beta_{i j B}$ is the coefficient of the $j^{\text {th }}$ category of the $i^{\text {th }}$ determinant in EDHS 2000

$\beta_{i j A}$ is the coefficient of the $j^{\text {th }}$ category of the $i^{\text {th }}$ determinant in EDHS 2016

$X_{i j B}$ is the proportion of the $j^{\text {th }}$ category of the $i^{\text {th }}$ determinant in EDHS 2000

$X_{i j A}$ is the proportion of the $j^{\text {th }}$ category of the $i^{\text {th }}$ determinant in EDHS 2016

The currently developed for the multivariate logistic decomposition analysis for the non-linear model for delayed first antenatal care visit using mvdcmp STATA package [21].

\section{Results}

\section{Background characteristics of women}

The following table showed that the individual characteristics of pregnant women in the five years preceding each survey in 2000, 2005, 2011, and 2016 EDHS datasets. Among the respondents, most of the respondents were age 20-34 years in all surveys. Based on educational levels, the proportion of women with no education decreased from $64.5 \%$ in 2000 to $53.9 \%$ in 2016 . But those with primary education increased from $21.2 \%$ in 2000 to $33.2 \%$ in 2016 over the study period and also those with secondary education and higher decreased from $14.3 \%$ in 2000 to $12.9 \%$ in 2016 . The proportion of their husbands with no education has decreased from $48 \%$ in 2000 to $40.1 \%$ in 2016 of the study periods.

Concerning the residence of respondents, in the four surveys about three-quarters of the respondents lived in the rural areas. In the four-consecutive surveys, most of the respondents $(>80 \%)$ had no ever terminated pregnancy over time. Based on the wantedness of pregnancy, the reporting of the women wanted then their pregnancy has increased from $56.9 \%$ in 2000 to $76 \%$ in 2016 . But the women wanted later their pregnancy and wanted no more pregnancy have decreased from $21.3 \%$ in 2000 to $17.3 \%$ in 2016 and from $21.8 \%$ in 2000 to $6.7 \%$ in 2016 respectively. Moreover, the reporting proportion of women who told about pregnancy complications has increased from $27.3 \%$ in 2000 to $45.0 \%$ in 2016 (Table 1).

Table 1: Characteristics and Percentage distribution of respondents in Ethiopia 


\begin{tabular}{|c|c|c|c|c|c|}
\hline & & Percenta & $\%)$ distribu & n of the $s$ & \\
\hline Chorentoriation ond thoir onts & & $\begin{array}{l}\text { EDHS } \\
2000\end{array}$ & $\begin{array}{l}\text { EDHS } \\
2005\end{array}$ & $\begin{array}{l}\text { EDHS } \\
2011\end{array}$ & $\begin{array}{l}\text { EDHS } \\
2016\end{array}$ \\
\hline - & & $N=2146$ & $N=2051$ & $N=3368$ & $\mathrm{~N}=4740$ \\
\hline women's age & $<20$ years & 6.6 & 5.7 & 4.7 & 5.3 \\
\hline & 20-34 years & 69.0 & 71.6 & 71.9 & 73.1 \\
\hline & $\geq 35$ years & 24.4 & 22.7 & 23.4 & 21.6 \\
\hline Household head & Male & 82.4 & 85.1 & 81.8 & 85.4 \\
\hline & Female & 17.6 & 14.9 & 18.2 & 14.6 \\
\hline & Rural & 71.7 & 78.5 & 73.1 & 81.6 \\
\hline Place of residence & Urban & 28.3 & 21.5 & 26.9 & 18.4 \\
\hline Women educational level & No education & 64.5 & 62.3 & 52.9 & 53.9 \\
\hline & $\begin{array}{l}\text { Primary } \\
\text { education }\end{array}$ & 21.2 & 23.1 & 37.2 & 33.2 \\
\hline & $\begin{array}{l}\text { Secondary \& } \\
\text { above }\end{array}$ & 14.3 & 14.6 & 9.9 & 12.9 \\
\hline Husband educational level & No education & 48.0 & 41.5 & 37.2 & 40.1 \\
\hline & $\begin{array}{l}\text { Primary } \\
\text { education }\end{array}$ & 28.4 & 33.2 & 45.9 & 40.8 \\
\hline & $\begin{array}{l}\text { Secondary \& } \\
\text { above }\end{array}$ & 23.6 & 25.3 & 16.9 & 19.1 \\
\hline Women occupation status & Working & 65.9 & 35.7 & 58.5 & 49.3 \\
\hline & Not working & 34.1 & 64.3 & 41.5 & 50.7 \\
\hline Husband occupation status & Not working & 0.5 & 0.9 & 0.9 & 5.8 \\
\hline & Working & 99.4 & 99.1 & 99.1 & 94.2 \\
\hline Reading newspapers & Yes & 15.9 & 14.7 & 16.8 & 10.0 \\
\hline & No & 84.0 & 85.3 & 83.2 & 90.0 \\
\hline Listening to a radio & Yes & 43.2 & 50.8 & 67.7 & 66.2 \\
\hline & No & 56.8 & 49.2 & 37.3 & 33.8 \\
\hline Watching television & Yes & 15.4 & 21.1 & 47.6 & 25.3 \\
\hline & No & 84.6 & 78.9 & 52.4 & 74.7 \\
\hline Told about pregnancy & Yes & 27.3 & 31.7 & 20.3 & 45.0 \\
\hline & No & 72.7 & 68.3 & 79.7 & 55.0 \\
\hline
\end{tabular}




\begin{tabular}{|c|c|c|c|c|c|}
\hline \multirow[t]{2}{*}{ Ever had terminated pregnancy } & Yes & 16.4 & 10.1 & 10.8 & 9.2 \\
\hline & No & 83.6 & 89.9 & 89.2 & 90.8 \\
\hline \multirow[t]{3}{*}{ Wantedness of pregnancy } & Wanted then & 56.9 & 60.3 & 68.0 & 76.0 \\
\hline & Wanted later & 21.3 & 21.5 & 21.7 & 17.3 \\
\hline & Wanted no more & 21.8 & 18.2 & 10.3 & 6.7 \\
\hline \multirow[t]{2}{*}{ Caesarean delivery } & Yes & 2.19 & 3.72 & 4.0 & 3.5 \\
\hline & No & 97.8 & 96.3 & 96.0 & 96.5 \\
\hline \multirow[t]{3}{*}{ Parity } & 1 & 37.7 & 40.0 & 41.1 & 41.2 \\
\hline & $2-4$ & 37.7 & 34.3 & 36.8 & 36.4 \\
\hline & $\geq 5$ & 24.6 & 25.7 & 22.1 & 22.4 \\
\hline \multirow[t]{3}{*}{ Family size } & $<=2$ & 2.5 & 1.9 & 3.3 & 2.1 \\
\hline & $3-4$ & 28.3 & 30.4 & 29.3 & 33.1 \\
\hline & $\geq 5$ & 69.2 & 67.7 & 67.4 & 64.8 \\
\hline \multirow[t]{3}{*}{ Number of living children } & 0 & 2.1 & 2.2 & 1.1 & 0.6 \\
\hline & $1-3$ & 60.8 & 57.1 & 60.9 & 59.3 \\
\hline & $\geq 4$ & 37.1 & 40.7 & 38.0 & 40.1 \\
\hline \multirow[t]{2}{*}{ Ever use contraceptive } & Yes & 18.4 & 24.7 & 38.4 & 41.9 \\
\hline & No & 81.6 & 75.3 & 61.6 & 58.1 \\
\hline \multirow[t]{11}{*}{ Region } & Tigray & 9.1 & 8.7 & 10.1 & 10.1 \\
\hline & Afar & 1.1 & 0.6 & 0.8 & 0.8 \\
\hline & Amhara & 19.3 & 23.8 & 23.7 & 23.0 \\
\hline & Oromia & 39.5 & 33.4 & 36.4 & 33.8 \\
\hline & Somali & 0.6 & 1.1 & 1.5 & 2.5 \\
\hline & $\begin{array}{l}\text { Benishangul- } \\
\text { Gumuz }\end{array}$ & 1.0 & 0.8 & 1.1 & 1.2 \\
\hline & SNNPR & 22.1 & 24.6 & 9.7 & 23.4 \\
\hline & Gambla & 0.6 & 0.4 & 0.5 & 0.3 \\
\hline & Harari & 0.4 & 0.3 & 0.3 & 0.3 \\
\hline & Addis Ababa & 5.6 & 0.5 & 5.4 & 4.0 \\
\hline & Dire Dawa & 0.7 & 0.6 & 0.5 & 0.6 \\
\hline
\end{tabular}




\section{Trends in delayed first ANC visit by selected variables}

The higher decrement in the proportion of delayed first antenatal care visits was observed in the last phase (2000-2016) with a $9.5 \%$ point change decreased compared with a $0.5 \%$ point change in the first phase (2000-2005). The trends of delayed first antenatal care visit proportion showed a variation in the women's characteristics. Among the rural residents, the highest decrement in the proportion of delayed first antenatal care visits was observed in the first phase of the study period (2000-2005) with $28.2 \%$ differences compared with $10.7 \%$ differences during (2000-2016).

Based on the region, the proportion of delayed first antenatal care visits was increased in the first phase (2000-2005) with a small 0.1\% point difference in the Amhara region but decreased in the last phase (20002016) at $19.0 \%$ point differences. The highest proportion of delayed first antenatal care visits was observed in the Dire-Dawa (24.9\%) and the least in the Somali region (1.1\%). Besides, the proportion of delayed first antenatal care visits for women with primary education in the sixth phase (2000-2016) was declined by a $10.1 \%$ point difference. Concerning women having two family sizes and three up to four-family sizes in households, the proportion of delayed first antenatal care visits over the study period (2000-2016) was decreased with $32.5 \%$ and $12.8 \%$ point changes respectively (Table 2 ).

Table 2: Trends of Delayed first antenatal care visits among women by the selected characteristics in Ethiopia. 


\begin{tabular}{|c|c|c|c|c|c|c|c|c|}
\hline \multirow[b]{2}{*}{ Characteristics } & \multirow{2}{*}{$\begin{array}{l}\text { EDHS } \\
2000 \\
\mathrm{~N}=2146\end{array}$} & \multirow{2}{*}{$\begin{array}{l}\text { EDHS } \\
2005 \\
\mathrm{~N}=2051\end{array}$} & \multirow{2}{*}{$\begin{array}{l}\text { EDHS } \\
2011 \\
N=3368\end{array}$} & \multirow{2}{*}{$\begin{array}{l}\text { EDHS } \\
2016 \\
N=4740\end{array}$} & \multicolumn{4}{|c|}{$\begin{array}{l}\text { Percentage point difference in } \\
\text { delayed first ANC visit }\end{array}$} \\
\hline & & & & & $\begin{array}{l}2000- \\
2005\end{array}$ & $\begin{array}{l}2005- \\
2011\end{array}$ & $\begin{array}{l}2011- \\
2016\end{array}$ & $\begin{array}{l}2000- \\
2016\end{array}$ \\
\hline \multicolumn{9}{|l|}{ Mother's age } \\
\hline$<20$ years & 83.4 & 79.7 & 75.4 & 63.5 & -3.7 & -4.3 & -12.0 & -19.9 \\
\hline 20-34 years & 76.3 & 75.7 & 73.3 & 67.0 & -0.7 & -2.3 & -6.3 & -9.3 \\
\hline$\geq 35$ years & 76.5 & 81.0 & 74.2 & 69.2 & 4.4 & -6.8 & -5.0 & -7.34 \\
\hline \multicolumn{9}{|l|}{ Residence } \\
\hline Rural & 81.6 & 53.4 & 78.9 & 71.0 & -28.2 & 25.5 & -7.9 & -10.7 \\
\hline Urban & 64.8 & 83.8 & 59.4 & 51.1 & 19.0 & -24.4 & -8.3 & -13.6 \\
\hline \multicolumn{9}{|l|}{ Household head } \\
\hline Male & 77.2 & 79.7 & 75.1 & 68.4 & 2.5 & -4.6 & -6.7 & -8.8 \\
\hline Female & 75.2 & 63.2 & 66.9 & 61.1 & -12.0 & 3.7 & -5.9 & -14.2 \\
\hline \multicolumn{9}{|l|}{ Women education } \\
\hline No education & 81.4 & 82.42 & 78.4 & 71.2 & 1.0 & -4.0 & -7.2 & -10.3 \\
\hline Primary education & 76.5 & 76.6 & 71.7 & 66.3 & 0.1 & -4.9 & -5.3 & -10.1 \\
\hline Secondary educat & 56.6 & 56.3 & 55.5 & 53.7 & -0.3 & -0.8 & -1.8 & -2.9 \\
\hline \multicolumn{9}{|l|}{ Husband education } \\
\hline No education & 81.7 & 81.84 & 78.4 & 69.5 & 0.1 & -3.5 & -8.9 & -12.3 \\
\hline Primary education & 79.4 & 84.2 & 75.6 & 70.4 & 4.8 & -8.6 & -5.2 & -9.0 \\
\hline $\begin{array}{l}\text { Secondary } \\
\text { education }\end{array}$ & 64.2 & 61.1 & 59.5 & 59.6 & -3.1 & -1.7 & 0.1 & -4.6 \\
\hline \multicolumn{9}{|l|}{$\begin{array}{l}\text { Wantedness of } \\
\text { pregnancy }\end{array}$} \\
\hline Wanted then & 73.6 & 77.4 & 74.4 & 66.9 & 3.8 & -2.9 & -7.6 & -6.7 \\
\hline Wanted later & 74.1 & 77.8 & 70.6 & 66.4 & 3.6 & -7.2 & -4.2 & -7.7 \\
\hline Wanted no more & 79.1 & 76.1 & 74.5 & 74.5 & -3.0 & -1.6 & 0.1 & -4.5 \\
\hline \multicolumn{9}{|l|}{ Women occupation } \\
\hline Working & 77.5 & 75.4 & 73.6 & 64.3 & -2.1 & -1.7 & -9.3 & -13.2 \\
\hline Not working & 75.5 & 78.3 & 73.7 & 70.2 & 2.8 & -4.6 & -3.5 & -5.2 \\
\hline
\end{tabular}


husband occupation

\begin{tabular}{lcccccccc} 
Working & 76.7 & 77.7 & 75.0 & 67.9 & 0.9 & -2.6 & -7.1 & -8.8 \\
\hline Not working & 80.9 & 81.1 & 45.4 & 67.3 & 0.2 & -35.7 & 21.8 & -13.6 \\
\hline Reading newspapers & & & & & & & & \\
\hline Yes & 63.8 & 61.1 & 65.3 & 51.7 & -2.7 & 4.1 & -13.5 & -12.1 \\
\hline No & 79.3 & 80.1 & 75.3 & 69.0 & 0.8 & -4.8 & -6.3 & -10.3 \\
\hline Listening to radio & & & & & & & & \\
\hline Yes & 71.0 & 70.4 & 72.5 & 65.2 & -0.6 & 2.1 & -7.3 & -5.8 \\
\hline No & 81.3 & 84.3 & 75.6 & 68.4 & 3.1 & -8.8 & -7.2 & -12.9 \\
\hline Watching television & & & & & & & & \\
\hline Yes & 60.6 & 55.8 & 68.8 & 54.8 & -4.8 & 13.0 & -14.0 & -5.8 \\
\hline No & 79.8 & 83.0 & 78.0 & 71.5 & 3.2 & $-5,0$ & -6.5 & -8.3 \\
\hline $\begin{array}{l}\text { Told pregnancy } \\
\text { complication }\end{array}$ & & & & & & & & \\
\hline Yes & 73.5 & 67.2 & 62.1 & 63.3 & -6.4 & -5.1 & 1.2 & -10.2 \\
\hline No & 78.2 & 81.8 & 76.2 & 70.7 & 3.6 & -5.7 & -5.6 & -7.6
\end{tabular}

Ever terminated

pregnancy

\begin{tabular}{lllllllll} 
Yes & 75.9 & 69.5 & 80.0 & 69.2 & -6.4 & 10.5 & -10.7 & -6.7 \\
\hline No & 77.0 & 78.1 & 72.8 & 67.1 & 1.1 & -5.3 & -5.7 & -9.9 \\
\hline Caesarean delivery & & & & & & & & \\
Yes & 57.6 & 49.0 & 63.8 & 37.2 & -8.6 & 14.8 & -26.6 & -20.4 \\
\hline No & 77.3 & 78.3 & 74.0 & 68.4 & 1.0 & -4.3 & -5.6 & -8.9 \\
\hline Parity & & & & & & & & \\
1 & 76.6 & 72.0 & 69.4 & 62.8 & -4.6 & -2.6 & -6.6 & -13.8 \\
$2-4$ & 77.4 & 79.1 & 76.1 & 66.9 & 1.7 & -3.0 & -9.2 & -10.5 \\
$\geq 5$ & 76.3 & 82.9 & 77.2 & 76.2 & 6.6 & -5.7 & -1.0 & -0.1
\end{tabular}

Family size

$\begin{array}{lllllllll}\leq 2 & 65.0 & 58.8 & 69.3 & 32.4 & -6.1 & 10.5 & -36.8 & -32.5 \\ 3-4 & 77.1 & 73.5 & 69.0 & 64.3 & -3.4 & -4.6 & -4.7 & -12.8 \\ \geq 5 & 77.1 & 79.4 & 75.9 & 69.9 & 2.3 & -3.6 & -5.9 & -7.2\end{array}$

Number of living 
children

\begin{tabular}{|c|c|c|c|c|c|c|c|c|}
\hline 0 & 71.8 & 60.8 & 70.0 & 26.9 & -11.1 & 9.3 & -43.2 & -45.0 \\
\hline $1-3$ & 76.6 & 74.1 & 72.4 & 63.7 & -2.4 & -1.8 & -8.7 & -12.9 \\
\hline$\geq 4$ & 77.6 & 82.5 & 75.7 & 73.3 & 4.9 & -6.8 & -2.4 & -4.3 \\
\hline \multicolumn{9}{|l|}{$\begin{array}{l}\text { Ever use } \\
\text { contraceptive }\end{array}$} \\
\hline Yes & 62.2 & 67.8 & 68.1 & 63.3 & 5.6 & 0.3 & -4.7 & 1.1 \\
\hline No & 80.1 & 80.4 & 77.1 & 70.2 & 0.2 & -3.3 & -6.9 & -10.0 \\
\hline \multicolumn{9}{|l|}{ Region } \\
\hline Tigray & 82.2 & 80.0 & 75.8 & 63.0 & -2.2 & -4.2 & -12.8 & -19.2 \\
\hline Afar & 80.6 & 73.6 & 68.9 & 63.2 & -7.0 & -4.7 & -5.7 & -17.4 \\
\hline Amhara & 77.5 & 77.6 & 73.9 & 58.5 & 0.1 & -3.7 & -15.5 & -19.0 \\
\hline Oromia & 74.6 & 75.5 & 75.9 & 71.2 & 0.9 & 0.4 & -4.7 & -3.4 \\
\hline Somali & 69.8 & 49.7 & 63.6 & 68.6 & -20.1 & 13.9 & 5.0 & -1.1 \\
\hline Benis-Gumuz & 81.8 & 82.2 & 84.3 & 76.9 & 0.4 & 2.2 & -7.4 & -4.8 \\
\hline SNNPR & 84.3 & 87,0 & 77.3 & 78.3 & 2.6 & -9.7 & 1 & -6.1 \\
\hline Gambla & 67.3 & 73.1 & 57.7 & 55.9 & 5.8 & -15.4 & -1.7 & -11.4 \\
\hline Harari & 59.7 & 55.7 & 44.6 & 41.4 & -3.9 & -11.1 & -3.2 & -18.2 \\
\hline Addis Ababa & 56.5 & 49.1 & 47.0 & 37.6 & -7.4 & -2.0 & -9.4 & -18.9 \\
\hline Dire Dawa & 56.0 & 46.1 & 42.0 & 31.1 & -9.9 & -4.1 & -10.9 & -24.9 \\
\hline Total & 76.8 & 77.3 & 73.6 & 67.3 & 0.5 & -3.7 & -6.3 & -9.5 \\
\hline
\end{tabular}

\section{Trends in the delayed first antenatal care visit}

The trends of delay first antenatal care visits over the study periods (2000-2016) were divided into different phases to observe the change in the delayed first antenatal care visits and important source for the change in the delayed first antenatal care visits. The proportion of delayed first antenatal care visits over the study period (2000-2016) has shown a decrement from $76.8 \%$ in 2000 to $67.3 \%$ in 2016 . The $95 \%$ confidence interval of the proportion of delay fist antenatal care visit rose a small from $76.8[75.1,78.6]$ to $77.3[75.4$, $79.1]$ decline to $73.6[72.1,75.1]$ and final decrease to $67.3[65.9,68.6]$. Therefore, the proportion of delayed first antenatal visit was significantly declined between EDHS 2000-2016 over time (Fig. 1).

\section{Decomposition analysis}

This multivariate decomposition analysis was used to examine the trends of delayed first antenatal care visit and identify factors either positively or negatively contributing to the change in the proportion of delayed first 
antenatal care visit.

\section{Decomposition analysis of delayed first ANC visit in Ethiopia, 2000-2016}

The decomposition of the change in the proportion of delayed first antenatal care visit by considering the selected variables is used to understand the variations in the composition of characteristics or the change in health behaviors. The overall trend from 2000 to 2016 noted that there was a significant decline in the delayed first antenatal care visit among pregnant women. The decline in the proportion of delayed first antenatal care visits over the study period has been described by the differences in the women's characteristics and the differences in the effect of characteristics (Table 3).

Table 3: Overall decomposition analysis change in delayed first antenatal care visit among women in Ethiopia 2000-2016.

\begin{tabular}{|lll|}
\hline Components & Coeff $(95 \% \mathrm{Cl})$ & Pct. \\
\hline Difference in characteristics(E) & $-.032592(-.056518,-.008665)$ & 39.1 \\
\hline Difference in coefficients(C) & $-.05091(-.089767,-.012034)$ & 60.9 \\
\hline Residual(R) & $-.083492(-.11491,-.052073)$ & \\
\hline
\end{tabular}

Table 4: Detailed decomposition analysis change in delayed first antenatal care visits among women in Ethiopia 2000-2016. 
Variables

$.0002138(-.002953$, $.003380)$

Coeff $(95 \% \mathrm{Cl})$

Household head

Male $^{\circledR}$

Female
Difference due to characteristics $(E)$

Difference due to coefficients

(C)

Pct. Coeff $(95 \% \mathrm{Cl})$

Pct.

Residence

Urban $^{\circledR}$

Rural

$.006818 *(.00095109$ $.012685)$

$-8.2 .0006295(-.048803$, $.0747)$

$-004131(-.018035$, .009773)

Reading newspapers

Yes $^{\circledR}$

No

$-.0036942(-.008142$,

$4.4 \quad-.029002(-.18088$, $.12287)$

Listening to a radio

Yes $^{\circledR}$

No

$-.004351 *(-.008333$,

$-.0003689)$

$5.2 \quad .018395(-.012632$, $.049422)$

Watching to television

Yes $^{\circledR}$

No

$-.007204 *(-.012087$,

$-.0023201)$

$\begin{array}{ll}8.6 \quad-.005452(-.019421, \\ & .008516)\end{array}$

6.5

Ever had terminated pregnancy

Yes $^{\circledR}$

No

$-.0003671(-.004347$, $.003613)$

$.4 \quad .002952(-.010704$, $.016608)$

Told about pregnancy complications

$\mathrm{Yes}^{\circledR}$

No

$-.0066515 *(-.012924$,

$-.0003792)$

$8.0 \quad .030205(-.015242$,

Cesarean delivery 


\begin{tabular}{|c|c|c|c|c|}
\hline \multicolumn{5}{|l|}{ Yes $^{\circledR}$} \\
\hline No & $\begin{array}{l}-.0002201 *(-.000355 \\
-.0000852)\end{array}$ & .3 & $\begin{array}{l}-.002895(-.007066 \\
.001276)\end{array}$ & 3.5 \\
\hline \multicolumn{5}{|l|}{ Wantedness of pregnancy } \\
\hline \multicolumn{5}{|l|}{ Wanted then ${ }^{\circledR}$} \\
\hline Wanted later & $\begin{array}{l}-.0000595(-.001919 \\
.001800)\end{array}$ & .1 & $\begin{array}{l}.0061642(-.010147 \\
.022476)\end{array}$ & -7.4 \\
\hline Want no more & $\begin{array}{l}-.007346(-.01921 \\
.0045191)\end{array}$ & 8.8 & $\begin{array}{l}.014025(-.0064513 \\
.034501)\end{array}$ & -16.8 \\
\hline \multicolumn{5}{|l|}{ Women education level } \\
\hline \multicolumn{5}{|l|}{ No education ${ }^{\circledR}$} \\
\hline Primary education & $\begin{array}{l}-.001951(-.007301 \\
.003407)\end{array}$ & 2.3 & $\begin{array}{l}.0007179(-.015125 \\
.01656)\end{array}$ & -.9 \\
\hline Secondary \& above education & $\begin{array}{l}.000176(-.000494 \\
.000845)\end{array}$ & -.2 & $\begin{array}{l}.013158(-.0024387 \\
.028755)\end{array}$ & -15.8 \\
\hline \multicolumn{5}{|l|}{ Husband education level } \\
\hline \multicolumn{5}{|l|}{ No education ${ }^{\circledR}$} \\
\hline Primary education & $.003822(-.0014566, .0091)$ & -4.6 & $\begin{array}{l}.009099(-.011995, \\
.030193)\end{array}$ & -10.9 \\
\hline Secondary education \& above & $\begin{array}{l}-.002262(-.004877 \\
.000354)\end{array}$ & 2.7 & $\begin{array}{l}.022655 \star(.0001921 \\
.04512)\end{array}$ & -27.1 \\
\hline \multicolumn{5}{|l|}{ Parity } \\
\hline \multicolumn{5}{|l|}{$1^{\circledR}$} \\
\hline $2-4$ & $\begin{array}{l}5.792 \mathrm{e}-05(-.0005397 \\
.0006556)\end{array}$ & -.1 & $\begin{array}{l}.002656(-.034132 \\
.039443)\end{array}$ & -3.2 \\
\hline$\geq 5$ & $\begin{array}{l}-.0007894(-.001665 \\
.00008664)\end{array}$ & .9 & $\begin{array}{l}.033711(-.002834 \\
.070257)\end{array}$ & -40.4 \\
\hline \multicolumn{5}{|l|}{ Family size } \\
\hline \multicolumn{5}{|l|}{$\leq 2^{\circledR}$} \\
\hline 3-4 & $\begin{array}{l}.0096351 *(.0027093, \\
.016561)\end{array}$ & -11.5 & $\begin{array}{l}.024385(-.035153, \\
.083923)\end{array}$ & -29.2 \\
\hline$\geq 5$ & $\begin{array}{l}-.0056901 *(-.010004 \\
-.001376)\end{array}$ & 6.8 & $\begin{array}{l}.047305(-.098709 \\
.19332)\end{array}$ & -56.7 \\
\hline \multicolumn{5}{|l|}{ Ever contraceptive use } \\
\hline $\mathrm{No}^{\circledR}$ & & & & \\
\hline
\end{tabular}




\begin{tabular}{|c|c|c|c|}
\hline Yes & $\begin{array}{l}-.008472(-.017782 \\
.000837)\end{array}$ & $\begin{array}{l}.008745(-.004505, \\
.02199)\end{array}$ & -10.5 \\
\hline Constant & & $\begin{array}{l}-.24466(-.48512 \\
-.0041945)\end{array}$ & 293 \\
\hline
\end{tabular}

ß: reference; *: significant at $5 \%$ level of significance; Pct: percent; Coef: coefficient

\section{Difference due to characteristics (Endowment)}

The multivariate decomposition analysis result showed that about $39 \%$ of the overall change in the delayed first antenatal care visit was due to a difference in characteristics or composition changes related to increased population access to antenatal care utilization (Table 3). Among the various important compositional factors, such as place of residence, listening to the radio, watching television, told about pregnancy complications, cesarean delivery and the number of family sizes in the household had a significant effect on the delayed first antenatal care visit (Table 4). In general, the decomposition results indicated that changes in health behavior were the principal source of change in the proportion of delayed first antenatal care visits among women between 2000 and 2016 regardless of the exposure variables.

An increase in the composition of women who reside in rural areas in the sample negatively contributes by $8.2 \%$ to the decline in the delayed first antenatal care visit. Decreasing in the composition of women who had no exposure to listening to the radio in the sample revealed that a significant positive contribution to delaying the first antenatal care visit, which contributes about $5.2 \%$ for the decline in delayed first antenatal care visit (Table 4).

A decrease in the proportion of women who were not told about pregnancy complications in the sample contributes a positive $8 \%$ for the decline of the proportion of delayed the first antenatal care visit. A decrease in the composition of women who had no experience of cesarean delivery in the sample revealed that a significant positive $0.3 \%$ contributes to the decline of delayed antenatal care visits among pregnant women (Table 4).

An increase in the composition of women who had three up to four-family sizes in the sample showed a significant negative $11.5 \%$ contributes to a decline in the proportion of delayed first antenatal care visit. While a decrease in the composition of women who had five and above family sizes in the house showed a significant positive contribution to the decline in the delayed the first antenatal care visit by contributing $6.8 \%$ (Table 4).

\section{Difference due to effects of the coefficient (effect of characteristics)}

Keeping the effect of change in compositional characteristics, about $61 \%$ of the overall change in the proportion of delayed first antenatal care visit was due to the differences in the effect of characteristics (Table 3). The husband's education factor had a significant effect on the observed positive change in the proportion of delayed first antenatal care visit. Women whose husband's education was secondary and above showed a significant positive contribution to the observed percentage decrease in the delayed first antenatal care visit over the study period which contributed about $27.1 \%$ (Table 4). 


\section{Discussion}

Delayed antenatal care is a major cause of pregnancy-related complications and the death of mothers and babies [22, 23]. This study explored the magnitude, trends, and identified the significant contributing factors of delayed first ANC visit in Ethiopia using the EDHS 2000-2016. The proportion of delayed first antenatal care visits declined from $76.8 \%$ in 2000 to $67.3 \%$ in 2016 . This finding was supported by the study done in Nigeria and Zimbabwe $[24,25]$. The possible reason for the decline in the trend of delayed first ANC visits could be due to the role of health extension workers in enhancing the maternal health care services and by providing adequate ANC services at the households and community level in Ethiopia [26]. Besides, the establishment of the Health Development Army(DHA) aimed to enhance the achievement of the Health Extension Program[24] and improve the health care accessibility to meet the primary target of the MDG agenda [27] might help in decreasing the trend of delayed first ANC visits.

In the decomposition analysis, the proportion of women who delayed the first antenatal care visit have been significantly declined over time. Therefore, understanding the potential sources of changes has public health advantage for assessing which are the contributing factors for the change in delayed first antenatal care visit and dealing with what is making progressively in the reducing delayed first antenatal care visit to evaluate the implemented strategies and work on the identified contributing factors for delayed first antenatal care visit.

This study showed that the contribution of behavior changes was more important than that of the composition changes which contributed by about $61 \%$ to the decline in the proportion of delayed first antenatal care visits in the past 15 years during the study period. About $39 \%$ of the change in the delayed first antenatal care visit over the study period 2000-2016 was observed due to the difference in the composition of women's characteristics over time. An increase in the composition of rural residing women showed a significant negative effect on delayed first antenatal care visits and contributed about $8.2 \%$ of the change in the delayed first antenatal care visit which implies that women residing in rural areas had delayed first antenatal care visit. This finding was supported by the study done in Vietnam, and Zambia [28, 29], in which women who lived in rural areas were initiated later and fewer antenatal care visits. The possible reason might be there is a lack of access to health care services in rural areas due to limited finances, the inaccessibility of health facilities and health care providers, lack of transportation services, and had no better opportunities for health information in the rural areas [30].

An increase in the composition of women who were not working showed a significant negative impact on the decline in the proportion of delayed first antenatal care visit. This finding was supported by the study done in public health centers in Addis Ababa, Ethiopia in which women who had no occupation were more likely to delay the first antenatal care visit [31]. The possible reason might be women who had no occupation were more likely to be economically dependent and consequently unable to access maternal health services recommended by health workers [32]. This implies that women who had no occupation or were not employed may not get important information about antenatal care visits from others in the workplace.

Decreasing in the composition of women who did not tell about pregnancy complications showed a significant positive contribution to the decline in the delayed first antenatal care visit. This finding was

Page 17/24 
supported by the study done in Malaysia and South Gondar, Ethiopia [33,34]. The possible reason might be the women may be aware of pregnancy complications and understanding the importance of antenatal care visits for pregnant women and fetuses. Besides, it suggests that health education had paramount importance in the improvement of the timing of ANC initiation and get intended to benefit early [35, 36]. This implies that most women were not aware of the risks of pregnancy, pregnancy danger signs, or when to begin in ANC women may prefer to wait four months before confirming their pregnancy and sharing the conditions with others.

The composition change by categories of the number of family size associated with both negative and positive contribution to the decline of delayed first antenatal care visit. An increase in the proportion of women who had three and four family size in the house negatively affected the proportion of delayed first antenatal care visit, while decreasing in the proportion of women who had five and above family size in the house positively affected the decline in the delayed first antenatal care visit. This finding was supported by studies done in Cameroon, Ethiopia [37, 38]. The possible explanation might be experienced a challenge to attend antenatal services due to time constraints considering their responsibilities for their children and health-related care services as well as resource constraints could affect health care utilization for treating pregnancy complications [39]. This result indicates that having a higher number of family sizes in the household may enhance the confidence of women to get delivered without attending early antenatal care visits and also may not give greater attention and care about the early antenatal care visits during the pregnancy period.

Decreasing in the composition populations in women who have not watched television and no listened to a radio program among women over the study period had a significant effect on the decline in the proportion of delayed the first antenatal care visit. This finding was supported by studies done in North India, South India, and Northern Ethiopia [40-42]. The possible reason might be women might access information about antenatal care and could understand the timing of the first antenatal care visit as well as get the awareness of where to go when they feel any pregnancy complications.

The composition change in the women who experienced a caesarean delivery among pregnant women over the study period had a significant impact on the decline in the proportion of delayed first antenatal care visit. This finding was supported by the study done in Australia [43]. This could be women who have had a previous caesarean delivery are aware of the risk of pregnancy complications and also have increased risks of uterine rupture, placenta previa, and ectopic pregnancy[44]. This implies that caesarean delivery has occurred in the advanced facility setting and had got information for the next pregnancy without happening of high illness or any pregnancy-related complications during antenatal care visits.

The husband's educational level was the only significant contributing factor for the decline in the delayed first antenatal care visit due to the effect of characteristics. The change in behavioral characteristics of the husband who were secondary and above educational level had a positive contribution to the decline in the delayed first antenatal care visit. This finding was supported by the other studies done in Ghana and Jamaica $[45,46]$, in which women's husbands had secondary and above educational levels were less likely to delay the first antenatal care visit. The possible reason could be the husband's education had a great role in improving awareness of health matters and the importance of ANC in particular. Advice from the husband 
may enable women to seek ANC and utilize the service early in pregnancy[47]. This result indicates that the husband's education had a significant effect on initiating women to understanding the importance of antenatal care visits for their pregnancy and educated husband accompany his wives for ANC.

\section{Conclusions}

Delayed first antenatal care visit had shown a significant decrease among pregnant women over the last fifteen years, but it was still high. The most important factors for the change in delayed first antenatal care visit were the place of residence, husband's education, told about pregnancy complications, cesarean delivery, family size, and the watching of television, and listening of radio to change in the proportion of delayed first antenatal care visit. Most of the change in delayed first antenatal care visit has been occurred due to the improvement of health care behaviors through health care providers on maternal health care services and the timing of the first antenatal care visit. Enhancing awareness about pregnancy complications in households and give information about the cause of poor pregnancy outcomes. From these findings, the interventions of public health such as health education and community communication education should primarily be given attention to the contributing factors to reduces delaying to the first ANC visit.

\section{Abbreviations}

AIC: Akaike's Information Criterion; ANC: Antenatal Care; Cl: Confidence Interval; DHA: Health Development Army; DHS: Demographic and Health Survey; EDHS: Ethiopian Demographic and Health Survey; HEP: Health Extension Program; USAID: U.S. Agency for International Development; WHO: World Health Organization.

\section{Declarations}

\section{Acknowledgments}

We would like to acknowledge the Demographic and Health Survey (DHS) program funded by the U.S. Agency for International Development (USAID) for the accusation dataset.

\section{Authors' contributions}

AAG participated in the conceptualization, inception of the design, data cleaning, data analysis, first draft, and approval of the manuscript. Both of them AAW and MWM prepared the final draft of the manuscript. Finally, all authors read and approved the manuscript.

\section{Funding}

No funding was obtained for this study.

\section{Availability of data}

The data was accessed from the online DHS database program by submitting the purpose to which the data were needed. The study used data from EDHS 2000 to 2016 (EDH data sets available on the public domain through the Measure DHS website (www.measuredhs.com). 
Ethical consideration

Ethical clearance approval was obtained from the institutional review board of the Institute of Public Health, College of Medicine and Health Science (CHMS), and the University of Gondar. Permission for downloading data was accessed from the public domain of the Demographic and Health Surveys (DHS) program through an online request http://www.dhsprogram.com.

Consent of publication

Not applicable.

Competing interests

No competing interests exist.

\section{References}

1. Organization WH: WHO recommendations on antenatal care for a positive pregnancy experience. 2016.

2. Wang W: Levels and trends in the use of maternal health services in developing countries: ICF Macro; 2011.

3. Ethiopian Federal Ministry of Health. Antenatal care module: 13. providing focused antenatal care. [https://www.open.edu/openlearncreate/mod/oucontent/view.php?id=44\&amp;printable=1]

4. UNICEF global databases, 2019 , based on MICS, DHS and other nationally representative household surveys. [https://data.unicef.org/topic/maternal-health/antenatal-care/\#]

5. CSA, ICF: Ethiopia Demographic and Health Survey 2016: Key Findings In.: Central Statistical Agency and ICF International Addis Ababa and Rockville, MD; 2017.

6. Raatikainen $\mathrm{K}$, Heiskanen $\mathrm{N}$, Heinonen $\mathrm{S}$ : Under-attending free antenatal care is associated with adverse pregnancy outcomes. BMC public health 2007, 7(1):268.

7. UNs. The Millennium Development Goals Report New york: 2015.

[https://www.un.org/millenniumgoals/2015_MDG_Report/pdf/MDG\%202015\%20rev\%20(July\%201).pdf]

8. Unicef. Maternal and newborn health [https://www.unicef.org/health/maternal-and-newborn-health]

9. Organization WH: Trends in maternal mortality 2000 to 2017: estimates by WHO, UNICEF, UNFPA, World Bank Group and the United Nations Population Division. 2019.

10. Tesfaye G, Loxton D, Chojenta C, Semahegn A, Smith R: Delayed initiation of antenatal care and associated factors in Ethiopia: a systematic review and meta-analysis. Reproductive health 2017, 14(1):150.

11. Ronsmans C, Graham WJ, group LMSSs: Maternal mortality: who, when, where, and why. The lancet 2006, 368(9542):1189-1200.

12. Organization WH: Making Pregnancy Safer-report by the secretariat. Geneva: WHO 2000.

13. Lawn J, Kerber K: Opportunities for Africa's Newborns: Practical data, policy and programmatic support for newborn care in Africa. Partnership for Maternal, Newborn and Child Health, Cape Town 2006, 32. 
14. Tesfaye G, Chojenta C, Smith R, Loxton D: Application of the Andersen-Newman model of health care utilization to understand antenatal care use in Kersa District, Eastern Ethiopia. PloS one 2018, 13(12):e0208729.

15. Tariku A, Melkamu Y, Kebede Z: Previous utilization of service does not improve timely booking in antenatal care: a cross-sectional study on timing of antenatal care booking at public health facilities in Addis Ababa. Ethiopian Journal of Health Development 2010, 24(3).

16. CSA, ICF: Ethiopia demographic and health survey 2000. 2001.

17. Macro, CSAEaO: Ethiopia demographic and health survey 2005. Addis Ababa, Ethiopia and Calverton Maryland, USA: Central Statistical Agency and ORC Macro 2006.

18. CSA[Ethiopia], ICF: International: Ethiopia Demographic and Health Survey 2011. Central Statistical Agency of Ethiopia and ICF International Addis Ababa, Ethiopia and Calverton, Maryland, USA 2012.

19. Tesfaye G, Chojenta C, Smith R, Loxton D: Application of the Andersen-Newman model of health care utilization to understand antenatal care use in Kersa District, Eastern Ethiopia. PloS one 2018, 13(12).

20. Fairlie RW: An extension of the Blinder-Oaxaca decomposition technique to logit and probit models. Journal of economic and social measurement 2005, 30(4):305-316.

21. Powers DA, Yoshioka H, Yun M-S: mvdcmp: Multivariate decomposition for nonlinear response models. The Stata Journal 2011, 11(4):556-576.

22. Organization WH: Trends in maternal mortality: 1990-2015: estimates from WHO, UNICEF, UNFPA, World Bank Group and the United Nations Population Division: World Health Organization; 2015.

23. Finlayson K, Downe S: Why do women not use antenatal services in low-and middle-income countries? A meta-synthesis of qualitative studies. PLoS Med 2013, 10(1):e1001373.

24. Fagbamigbe AF, Mashabe B, Lepetu L, Abel C: Are the timings and risk factors changing? Survival analysis of timing of first antenatal care visit among pregnant women in Nigeria (2003-2013). International journal of women's health 2017, 9:807.

25. ZIMSTAT Z: Zimbabwe Demographic and Health survey 2015-16. Calverton, Maryland USA: Zimbabwe National Statistics Agency \& ICF International 2016.

26. Medhanyie A, Spigt M, Kifle Y, Schaay N, Sanders D, Blanco R, GeertJan D, Berhane Y: The role of health extension workers in improving utilization of maternal health services in rural areas in Ethiopia: a cross sectional study. BMC health services research 2012, 12(1):352.

27. Assefa Y, Van Damme W, Williams OD, Hill PS: Successes and challenges of the millennium development goals in Ethiopia: lessons for the sustainable development goals. BMJ global health 2017, 2(2):e000318.

28. Trinh LTT, Dibley MJ, Byles J: Determinants of antenatal care utilization in three rural areas of Vietnam. Public Health Nursing 2007, 24(4):300-310.

29. Banda I, Michelo C, Hazemba A: Factors associated with late antenatal care attendance in selected rural and urban communities of the copperbelt province of Zambia. Medical Journal of Zambia 2012, 39(3):29-36.

30. Yesuf EA, Calderon-Margalit R: Disparities in the use of antenatal care service in Ethiopia over a period of fifteen years. BMC pregnancy and childbirth 2013, 13(1):131. 
31. Gulema $\mathrm{H}$, Berhane $\mathrm{Y}$ : Timing of first antenatal care visit and its associated factors among pregnant women attending public health facilities in Addis Ababa, Ethiopia. Ethiopian journal of health sciences 2017, 27(2):139-146.

32. Gebrekidan K, Worku A: Factors associated with late ANC initiation among pregnant women in select public health centers of Addis Ababa, Ethiopia: unmatched case-control study design. Pragmatic and observational research 2017, 8:223.

33. Jiee SFA: Late Antenatal Booking and its Predictors in Lundu District of Sarawak, Malaysia. International Journal of Public Health Research 2018, 8(2):956-964.

34. Wolde HF, Tsegaye AT, Sisay MM: Late initiation of antenatal care and associated factors among pregnant women in Addis Zemen primary hospital, South Gondar, Ethiopia. Reproductive health 2019, 16(1):73.

35. Obermeyer CM, Potter JE: Maternal health care utilization in Jordan: a study of patterns and determinants. Studies in family planning 1991, 22(3):177-187.

36. Titaley CR, Dibley MJ, Roberts CL: Factors associated with underutilization of antenatal care services in Indonesia: results of Indonesia Demographic and Health Survey 2002/2003 and 2007. BMC public health 2010, 10(1):485.

37. Tolefac PN, Halle-Ekane GE, Agbor VN, Sama CB, Ngwasiri C, Tebeu PM: Why do pregnant women present late for their first antenatal care consultation in Cameroon? Maternal health, neonatology and perinatology 2017, 3(1):29.

38. Ejeta E, Dabsu R, Zewdie O, Merdassa E: Factors determining late antenatal care booking and the content of care among pregnant mother attending antenatal care services in East Wollega administrative zone, West Ethiopia. Pan African Medical Journal 2017, 27(1).

39. Abor PA, Abekah-Nkrumah G, Sakyi K, Adjasi CK, Abor J: The socio-economic determinants of maternal health care utilization in Ghana. International Journal of Social Economics 2011.

40. Geta MB, Yallew WW: Early initiation of antenatal care and factors associated with early antenatal care initiation at health facilities in southern Ethiopia. Advances in Public Health 2017, 2017.

41. Pallikadavath S, Foss M, Stones RW: Antenatal care: provision and inequality in rural north India. Social science \& medicine 2004, 59(6):1147-1158.

42. Navaneetham K, Dharmalingam A: Utilization of maternal health care services in Southern India. Social science \& medicine 2002, 55(10):1849-1869.

43. Trinh LTT, Rubin G: Late entry to antenatal care in New South Wales, Australia. Reproductive Health 2006, 3(1):8.

44. Minkoff H, Chervenak FA: Elective primary cesarean delivery. New England Journal of Medicine 2003, 348(10):946-950.

45. Doku D, Neupane S, Doku PN: Factors associated with reproductive health care utilization among Ghanaian women. BMC international health and human rights 2012, 12(1):29.

46. McCaw-Binns A, La Grenade J, Ashley D: Under-users of antenatal care: a comparison of non-attenders and late attenders for antenatal care, with early attenders. Social science \& medicine 1995, 40(7):10031012. 
47. Boerleider AW, Wiegers TA, Manniën J, Francke AL, Devillé WL: Factors affecting the use of prenatal care by non-western women in industrialized western countries: a systematic review. BMC pregnancy and childbirth 2013, 13(1):81.

\section{Figures}

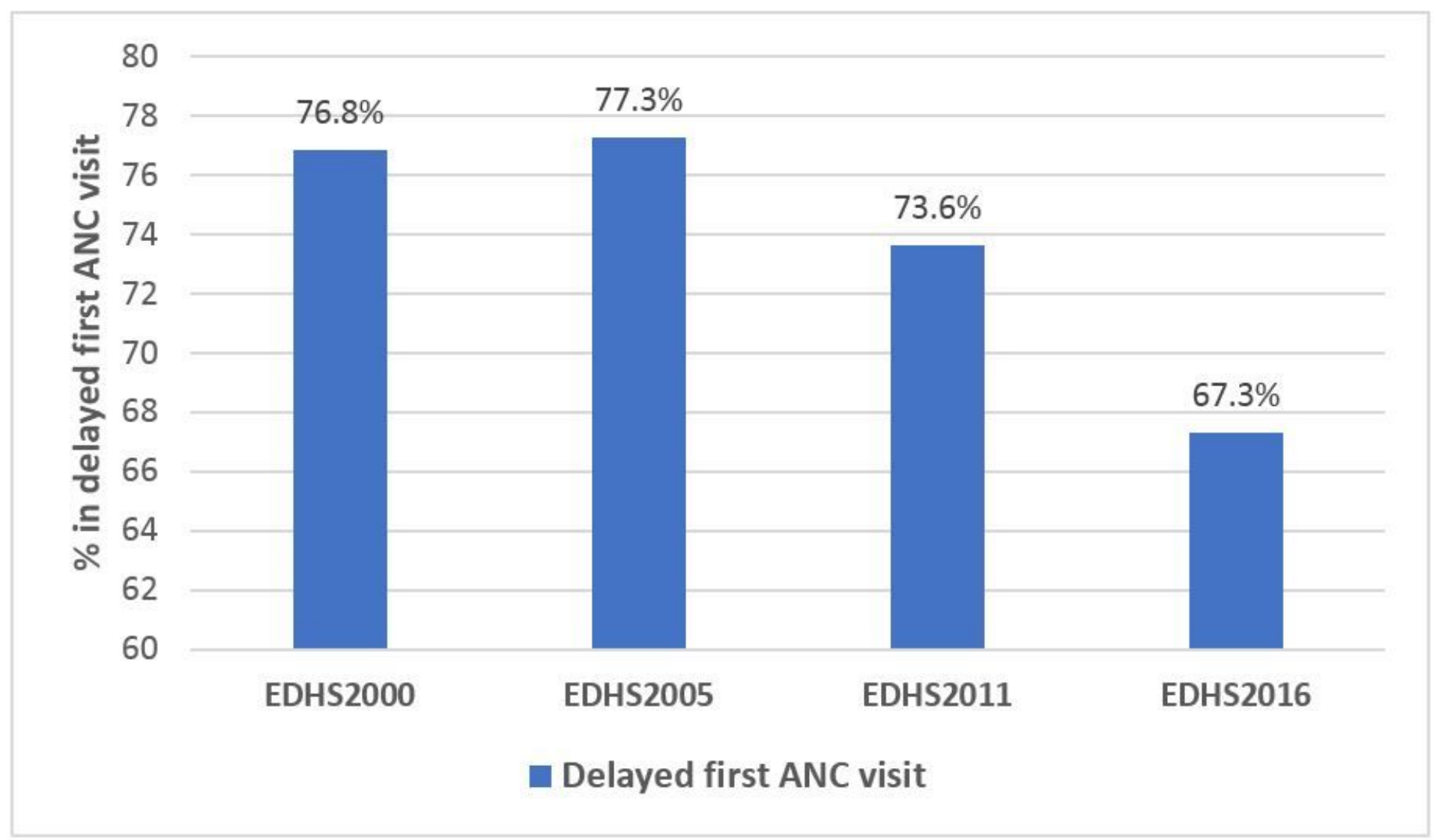

\section{Figure 1}

The trends of delayed first ANC visits in Ethiopia from 2000 to 2016. 


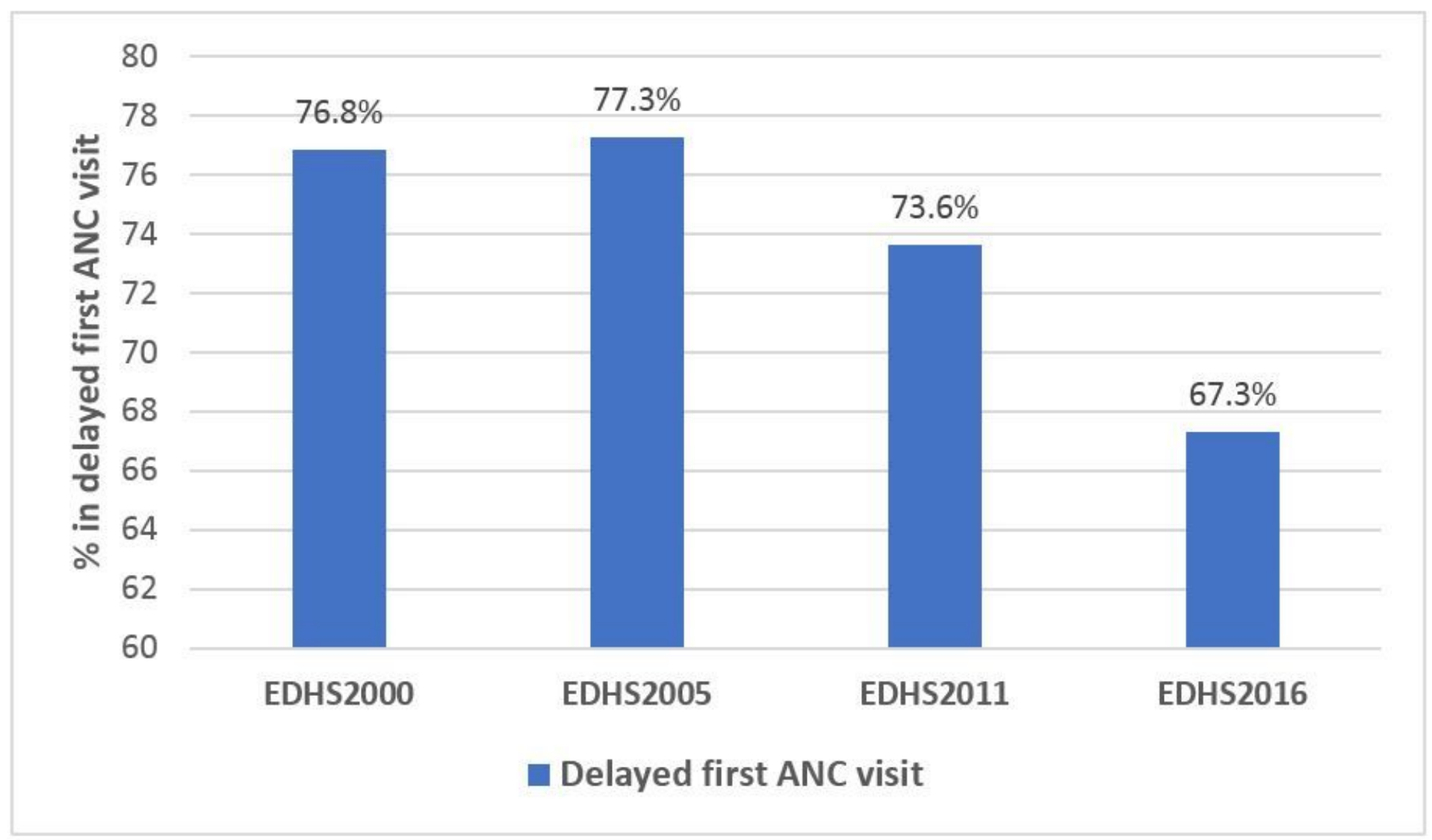

Figure 1

The trends of delayed first ANC visits in Ethiopia from 2000 to 2016. 